\title{
ANÁLISE DO COMPORTAMENTO DOS PREÇOS DO BOI GORDO E DO BOI MAGRO ENTRE 2000 E 2012
}

\author{
Andréia Moreira da Fonseca Boechat ${ }^{2}$
}

Resumo: O presente artigo tem como objetivo analisar os efeitos do choque nos preços do boi gordo sobre o comportamento dos preços do boi magro no período compreendido entre outubro de 2000 até outubro de 2012. A metodologia utilizada foi a análise dos Testes de Raiz Unitária de Dickey-Fuller Aumentado (ADF), de Causalidade de Granger, Cointegração de Johansen, o Método Autorregressivo (VAR), decomposição dos erros da variância e a função impulso-resposta. Os resultados mostraram relação entre os preços dos dois mercados selecionados, confirmando a hipótese de que o preço do boi gordo influencia na formação do preço do boi magro no curto prazo.

Palavras-Chave: Preços, Modelo VAR, Bovinos; Transmissão de preços.

Abstract: This article aims to analyze the effects of the shock on prices of cattle on the behavior of prices of feeder cattle in the period October 2000 to October 2012. The methodology used was the analysis of Unit Root Tests of Dickey-Fuller (ADF), Granger Causality, Johansen Co-Integration, Method Auto-Regressive (VAR), error variance decomposition and impulse response function. The results showed that there is a relationship between the prices of the two selected markets, confirming the hypothesis that the price of cattle influences the formation of the price of feeder cattle in the short term.

Keywords: Price, VAR model, Cattle; Transmission prices

Recebido em: 16/01/14; Aceito em: 17/09/2014.

2 Doutoranda em Teoria Econômica pela Universidade Estadual de Maringá (UEM). E-mail: amfboechat@, gmail.com 


\section{Introdução}

Na década de 1990, o Brasil passou por diversas transformações. As principais mudanças foram: a estabilização econômica, decorrida do plano Real; a maior abertura da economia às importações; a concorrência com produtos importados, que estimulou as empresas nacionais a investir em novas tecnologias de produtos, processo e gestão; concentração na agropecuária, na indústria de alimentos e na distribuição; relocalização ou implantação de novas unidades agroindustriais devido ao deslocamento da fronteira agrícola brasileira em direção ao Centro-Oeste; e aumento da expectativa de vida e redução do número de habitantes por domicílio (BATALHA, 2002). Outra mudança ocorrida no final da década de 1990 foi a desvalorização da moeda brasileira, que impulsionou as exportações de carne bovina e aumentou os investimentos no agronegócio. Neste período também houve aumento da competição no mercado de carnes, em razão do aumento do consumo da produção de aves e suínos. Estes fatores fizeram melhorar a produtividade para poder competir no mercado, tanto nacional quanto internacional (BATALHA; BUAINAIN, 2007).

O setor de carne bovina brasileiro destaca-se no cenário internacional em virtude de o Brasil deter o maior rebanho comercial do mundo, 187 milhões de cabeças, e a produção de 9,1 milhões de toneladas de carne por ano, além de o país ser o maior exportador do produto do mundo, cerca de 1,9 milhões de toneladas por ano (FAO, 2010).

Mesmo diante deste quadro, o setor apresenta baixa produtividade, se comparado com outros países, e baixa coordenação dos agentes, se comparado com outros setores de carne, como o de aves. Outra característica é a criação de gado a pasto, vulnerável às questões climáticas.

Porém, essa liderança acarretou algumas dificuldades, principalmente em relação à imposição de restrições sanitárias à carne brasileira de algumas regiões, o que fez com que as empresas do setor estivessem em constante transformação, além de alteração na oferta de carne bovina e, consequentemente, nos preços dos animais. 
Diante do contexto apresentado, analisar o comportamento dos preços, em especial do boi gordo e do boi magro, é de suma importância, por ser indispensável o planejamento adequado da atividade em questão. Por esta razão, o presente artigo tem como objetivo examinar o comportamento dos preços do boi gordo e do boi magro na pecuária brasileira, entre outubro de 2000 a outubro de 2012, tendo como hipótese que variações no preço do boi gordo influenciam os demais elos da cadeia, incluindo o boi magro.

\section{A cadeia produtiva da carne bovina}

Nos últimos anos, o sistema agroindustrial de carne bovina vem passando por rápidas e profundas transformações, seguidas por uma dinâmica competitiva e um quadro institucional em alteração, sendo necessário que os agentes que compõem o sistema sejam capazes de responder eficaz e eficientemente às novas tendências de consumo. Em razão dessas novas tendências, houve necessidade de uma reestruturação produtiva, que consistiu no aumento da concentração das empresas distribuidoras de alimentos, alterando o poder de negociação no interior das cadeias agroindustriais; no aumento da utilização de tecnologias de informações; e na necessidade da gestão eficiente da cadeia de suprimentos para poder acompanhar a tendência de disponibilizar aos consumidores produtos cada vez mais frescos (BATALHA, 2002).

\subsection{O setor de criação de gado de corte}

A produção de bovinos de corte é composta por três fases: cria, recria e engorda. A primeira fase vai da reprodução até o desmame do bezerro. A segunda fase começa quando o bezerro é desmamado e termina com o gado indo para engorda ou para a criação como reprodutores ou matrizes. Nesta fase, o boi é chamado de boi magro. Na última fase, a da engorda, os bois são engordados até chegarem ao ponto ideal de abate. Neste caso, os bois gordos são vendidos aos frigoríficos, que abastecem o mercado 
consumidor. Para cada fase, um produto é "criado" e há um mercado consumidor em que os animais são comercializados e, consequentemente, o preço é definido (SACHS \& PINATTI, 2007).

\subsection{Sazonalidade, ciclo da pecuária e tendência}

Os preços do gado vivo passam por leve sazonalidade. Estes preços estão relacionados à disponibilidade do boi gordo, que, por sua vez, está relacionado à disponibilidade de pastagens ao longo do ano. Este ciclo é conhecido como ciclo pecuário, que, segundo Toledo e Santiago (1984), é aquele em que a queda na cotação do boi acarreta redução das cotações das fases intermediárias até que as matrizes sejam descartadas, acentuando o excesso de oferta de carne bovina e queda nos preços.

A sazonalidade pode ser observada tanto na produção quanto no consumo e é uma das características da maioria das cadeias produtivas agroindustriais, acarretando diversas consequências no funcionamento dos agentes da cadeia, principalmente na volatilidade dos preços (BATALHA; BUAINAIN, 2007). Carvalho (2008 apud MACEDO, 2004) cita que, ao analisar o mercado de carne, identifica-se outro tipo de sazonalidade, a da demanda interna, já que, no início do mês, quando a maior parte da população recebe seu salário, aumenta a procura por carne bovina no varejo, consequentemente, aumenta a demanda de toda a cadeia agroindustrial. Outro fator citado pelo mesmo autor é que a carne de frango e suína, como são produtos substitutos, redirecionam parte da demanda para a carne bovina quando o preço aumenta.

Em relação ao ciclo da pecuária brasileira, Martins et al. (2009) afirmam que o mecanismo gerador dos ciclos é o seguinte: quando a oferta de carne bovina está elevada em relação à demanda efetiva, os preços da carne no varejo e no atacado caem, sendo que a queda dos preços dos animais de reposição costuma ser mais intensa do que a ocorrida nos animais gordos. Com isso, o criador que produz bezerros tem perda de receita e é obrigado a vender suas matrizes para abate, fazendo com que 
se agrave o desequilíbrio entre oferta e demanda de carne, acarretando novas rodadas de redução de preço.

Para Nehmi Filho (2007), as flutuações na produção de carne bovina estão ligadas à maior proporção de vacas nos frigoríficos. Quando o rebanho se estabiliza, o abate de fêmeas é limitado a matrizes descartadas no processo de produção, seja por velhice ou por infertilidade. No atual estágio da pecuária brasileira, o equilíbrio se dá quando o abate de fêmeas equivale a mais ou menos $45 \%$ do total.

Outro aspecto ligado ao chamado "ciclo do boi" ${ }^{3}$ está associado à renovação do rebanho e às oscilações do mercado. Preços baixos, custos de insumos elevados ou exigências de adaptação tecnológica, associados a práticas inadequadas, demandam investimentos ou comprometem a receita do produtor rural. Como reação, os produtores se desfazem de suas matrizes, reduzindo a capacidade de produção no curto e médio prazo, elevando os preços e estimulando novos investimentos, elevando os níveis de produção. Os principais indicadores são os preços do boi gordo e o descarte de matrizes (BATALHA; BUAINAIN, 2007).

Para analisar a sazonalidade e o ciclo da pecuária de gado de corte, é necessário examinar a evolução do preço da carne bovina e da arroba. De acordo com Batalha (2007), apesar de a conjuntura externa ser favorável ao aumento das exportações brasileiras, em razão das mudanças tecnológicas que vêm sendo implementadas (na indústria frigorífica, estão sendo difundidas ferramentas de gestão e tecnologia que levam a um melhor desempenho na produção, como práticas que permitem melhorar os controles sanitários e ambiental) e dos baixos custos da mão de obra e da terra, ainda existem obstáculos a serem superados, tais como superação das barreiras sanitárias; desenvolvimento de um padrão de qualidade e seu reconhecimento pelo mercado importador; constituição de uma cadeia mais bem coordenada; superação de limitantes de exportação como quotas, tarifas e concorrência subsidiada; e colocação de produtos de maior valor agregado.

3 Preço do boi gordo 


\section{Procedimentos metodológicos}

\subsection{Natureza dos dados}

Para analisar o comportamento dos preços do boi gordo e do boi magro, foram utilizadas duas séries temporais com observações mensais para as seguintes variáveis: cotação de preço nominal do boi gordo em arroba e cotação nominal do boi magro em unidade. Os dados foram obtidos na Secretaria de Agricultura e Abastecimento do Estado do Paraná - Seab e no Instituto de Economia Agrícola-IEA, em suas médias históricas mensais, no período entre outubro de 2000 e outubro de 2012.

Os preços do boi gordo e do boi magro foram utilizados na forma nominal, ao invés de real, pois, segundo Sachs e Pinatti (2008), o uso de deflatores pode contaminar as séries, inserindo elementos diferentes à série original, podendo levar à identificação de modelos deturpados, em razão da metodologia escolhida. Pinho e Rocha (1994) acrescentam que se pode trabalhar com séries de tempo nominais em razão de as séries deflacionadas se aproximarem ao modelo com séries sem deflação, dependendo da metodologia empregada na pesquisa.

\subsection{Método}

\subsubsection{Teste de raiz unitária}

Gujarati (2010) observa que grande parte dos estudos baseados em séries temporais admite que essas séries sejam estacionárias, ou seja, tenham média, variância e auto-covariância constantes, independentemente do ponto de medição.

Para determinar a estacionaridade ou não do modelo proposto, são utilizados dois métodos principais: o teste de Phillips-Perron (PP) e o teste 
de Dickey-Fuller aumentado (ADF). Segundo Gujarati (2006), o teste PP utiliza métodos estatísticos não paramétricos para testar a correlação serial dos erros sem adicionar os termos de diferença defasados. Já o teste ADF é utilizado em casos nos quais os erros são correlacionados e é conduzido por aumento das equações do teste Dickey-Fuller, devido ao acréscimo dos valores defasados da variável dependente.

Para testar a presença ou não de raiz unitária, além da ordem de integração, foi utilizado o teste ADF, desenvolvido por Dickey-Fuller (1981), com a seguinte base:

$$
\Delta Y_{\tau}=\beta+\delta T+\gamma Y_{\tau-1}+\alpha_{i} \sum_{j=1}^{m} \Delta Y_{\tau-1}+\epsilon_{\tau}
$$

Em que Y é a série de preços; $\beta$ é a constante; $\mathrm{T}$ é a tendência; e $\Delta$ é o operador de diferença.

A hipótese nula é que existe raiz unitária (série não estacionária) e a hipótese alternativa é que a série é estacionária. $\mathrm{O}$ número de termos defasados é, muitas vezes, de acordo com Gujarati (2010), determinado empiricamente.

\subsubsection{Teste de causalidade de Granger}

Para verificar a causalidade entre as variáveis, será utilizado o teste de causalidade de Granger, que, segundo Granger (1969 apud SACHS e PINATTI, 2008), diz que a variável X causará a variável y no sentido de Granger, quando os valores passados de $\mathrm{X}$ ajudarem a prever o comportamento futuro de $\mathrm{Y}$, ao invés de utilizar somente valores passados de B. Os mesmos autores observam que este teste deve ser conduzido com as variáveis estacionárias, conforme equação abaixo. 


$$
y_{t}=\sum_{j=1}^{p} \gamma_{j} y_{t-j}+\sum_{j=1}^{p} \theta_{j} x_{t-j}+\varepsilon_{t}
$$

A comprovação da causalidade entre $X$ e $Y$ consiste em testar se os coeficientes de $X$ são nulos. Desse modo, tal verificação é feita pelo teste F. No presente trabalho, o modelo procura estimar uma equação da variável X (preço do boi gordo) em função de Y (preço do boi magro), para possibilitar identificar se uma causa a outra.

\subsubsection{Teste de cointegração}

O teste de cointegração procura identificar se duas ou mais variáveis integradas, de mesma ordem, têm relação de equilíbrio no longo prazo (SACHS e PINATTI, 2008). Segundo os mesmos autores, a interpretação econômica da cointegração é que existe uma relação de equilíbrio de longo prazo entre as séries. Neste caso, mesmo que as séries não sejam estacionárias, apresentam tendência conjunta de longo prazo. Resumindo, o conceito de cointegração mimetiza a existência de um equilíbrio de longo prazo, para o qual um sistema econômico converge ao longo do tempo.

Para verificar a existência de cointegração, o presente estudo optou pela abordagem de Johansen (1988), porque, além de revelar a existência ou não de cointegração, permite obter o número de vetores de cointegração entre as variáveis. Neste processo, segundo Dantas e Weydmann (2008), é construído um modelo VAR, que pode ser descrito como:

$X_{t}=A_{0+} A_{1} X_{t-1}+\cdots+A_{k} X_{t-k}+\epsilon_{t}$

Em que X é o vetor das " $n$ " variáveis de mesma ordem; $A_{o}$ é a matriz de interceptos "n"x1; $A_{i}$ é a matriz de coeficientes $\mathrm{n}$ x n; e $\varepsilon_{\mathrm{t}}$ é o vetor de termos de erros $\mathrm{n} \times 1$. 
Segundo Dantas e Weydmann (2009), o primeiro passo para fazer o teste de Johansen é determinar a ordem de defasagens da variável dependente, pois este procedimento tem como hipótese que, pela introdução de um número suficiente de defasagens, é possível obter uma estrutura de resíduos estacionários. Posteriormente, é preciso observar o termo que contém os componentes da velocidade de ajustamento dos parâmetros no curto prazo e a matriz de coeficientes de cointegração no longo prazo.

\subsubsection{Modelo autorregressivo vetorial (VAR)}

Os efeitos dinâmicos de choque do preço do boi gordo sobre o preço do boi magro foram analisados pelo modelo autorregressivo vetorial-VAR, que, segundo Sachs e Pinatti (2008), é uma metodologia indicada para estimar modelos que envolvem relações complexas das variáveis. É importante observar que o modelo Var não separa variáveis endógenas ou exógenas, pois busca a simultaneidade das equações, bem como a causalidade das variáveis. Assim, todas as variáveis são tratadas igualmente, sem que haja qualquer tipo de distinção, conforme modelo abaixo.

$$
Y_{t}=\varphi_{1} y_{t-1}+\varphi_{\mathbf{2}} Y_{t-\mathbf{2}}+\cdots+\varphi_{t} y_{t-p}+\epsilon
$$

Em que y é um vetor $\mathrm{n} x 1$; $\Phi$ é uma matriz de coeficientes de ordem $\mathrm{K}$ $\mathrm{x} \mathrm{K}$; e $\varepsilon$ é o vetor coluna de erros que contém um processo ruído branco.

\subsubsection{Decomposição da variância}

A decomposição da variância fornece o percentual do erro da variância prevista atribuída aos choques de determinada variável aos choques nas demais variáveis do modelo. Se os choques observados em z não forem capazes de explicar a variância do erro de previsão da variável y, podese dizer que y é exógeno; caso contrário, y é endógeno (MAYORGA et al., 2009) 


\subsubsection{Função de impulso-resposta}

Segundo Gujarati (2010), é complexo interpretar os coeficientes do modelo VAR estimado, por esta razão, é adotada a técnica chamada função impulso-resposta - IRF, que rastreia a resposta da variável dependente no sistema VAR e choques no termo de erro a choques no termo de erro, em outras palavras, identifica o impacto de choques no atual período em períodos futuros.

\section{Resultados e discussões}

Nesta seção, serão apresentados os resultados dos testes de raiz unitária, causalidade de Granger, de cointegração, do modelo autorregressivo vetorial (VAR), decomposição da variância e, por último, a função impulso resposta, que foram obtidos com base nos preços do boi gordo e do boi magro e do software estatístico Stata 11.0. Para melhor entendimento dos dados, a Tabela 1 apresenta as estatísticas descritivas das séries temporais de preço do boi gordo e do boi magro.

Tabela 1 - Estatística Descritiva dos preços do boi gordo e do boi magro no período entre outubro de 2000 a outubro de 2012.

\begin{tabular}{lll}
\hline Estatísticas & Preço do boi gordo & Preço do boi magro \\
\hline Média & 63,5706 & 752,311 \\
Máximo & 100,88 & 1277,25 \\
Mínimo & 37,14 & 412,56 \\
Desvio padrão & 18,7472 & 262,771 \\
Observações & 145 & 145 \\
\hline
\end{tabular}

Fonte: Dados baseados na Seab e IEA (2012)

Como pode ser visto na Tabela 1 e conforme dados da Seab (2012) e do IEA (2012), o preço máximo do boi gordo no período analisado foi de $\mathrm{R} \$ 100,88$ a arroba em novembro de 2010 e de $\mathrm{R} \$ 1277,25$ a unidade do 
boi magro em maio de 2011. Já o preço mínimo no mesmo período foi de $\mathrm{R} \$ 37,14$ em fevereiro de 2001 e de $\mathrm{R} \$ 412,56$ em outubro de 2000 para boi gordo e boi magro, respectivamente. Nas séries utilizadas para a análise, o desvio padrão foi de 18,7472 para o boi gordo e de 262,771 para o boi magro, e o preço médio foi de $\mathrm{R} \$ 63,5706$ e $\mathrm{R} \$ 752,311$, respectivamente. Faz-se mister lembrar que, em razão da metodologia escolhida, os preços das séries selecionadas não foram deflacionados.

Para melhor análise do modelo, é necessário efetuar algumas técnicas estatísticas, sendo antes necessário verificar se as séries temporais são estacionárias. Para isto, foi feito o teste Dickey-Fuller Aumentado (ADF).

O teste ADF foi estimado em três situações: i) sem intercepto e sem tendência; ii) sem tendência e com intercepto; e iii) modelo completo (com tendência e com intercepto). Para a escolha do número de lags, foram utilizados os critérios de Akaike e Schwartz, que indicam uma defasagem, conforme Tabela 2 .

Tabela 2 - Teste de Raiz Unitária de Dickey-Fuller Aumentado (ADF) e a ordem de integração

\begin{tabular}{llllll}
\hline \multirow{2}{*}{ Série } & Lag & \multicolumn{3}{c}{ ADF } & Ordem de \\
\cline { 3 - 5 } & & $\mathbf{T}$ & $\boldsymbol{\tau}_{\boldsymbol{\mu}}$ & $\boldsymbol{\tau}_{\boldsymbol{\tau}}$ & Integração \\
\hline Nível & & & & & \\
\hline Preço do boi gordo & 1 & 1,247 & $-0,642$ & $-1,635$ & $\mathrm{I}(1)$ \\
Preço do boi magro & 1 & 1,555 & $-0,657$ & $-2,428$ & $\mathrm{I}(1)$ \\
\hline Primeira diferença & & & & & \\
\hline Preço do boi gordo & 1 & $-7,209$ & $-7,425$ & $-7,407$ & $\mathrm{I}(1)$ \\
Preço do boi magro & 1 & $-8,410$ & $-8,737$ & $-8,705$ & $\mathrm{I}(1)$ \\
\hline
\end{tabular}

$\mathrm{T}$ - sem tendência e sem intercepto

$\tau_{\mu-}$ sem tendência e com intercepto

$\tau_{\tau_{-}}$modelo completo (com tendência e com intercepto)

Fonte: Dados baseados na Seab e IEA (2012) 
A Tabela 2 mostra que as variáveis em nível não são estacionárias, não podendo ser rejeitada a hipótese nula de que há raiz unitária. Os testes em primeira diferença mostram que as séries são estacionárias, sendo assim, a hipótese nula é rejeitada, o que significa que as séries em nível são integradas de ordem 1.

Após verificar o comportamento das séries temporais, foram feitos o teste de causalidade de Granger, o teste de cointegração e a estimação da função impulso resposta. Para verificar o grau de relacionamento entre as variáveis do modelo proposto, foi feito o teste de causalidade de Granger, tendo como hipótese nula que o preço do boi gordo não causa, no sentido de Granger, o preço do boi magro. O resultado do teste pode ser visto na Tabela 3 .

Tabela 3 - Resultados dos testes de causalidade de Granger para as variáveis preço do boi gordo e preço do boi magro entre outubro de 2000 e outubro de 2012

\begin{tabular}{lccc}
\hline \multicolumn{1}{c}{ Teste } & $\begin{array}{c}\text { Qui- } \\
\text { quadrado }\end{array}$ & $\begin{array}{c}\text { Graus de } \\
\text { liberdade }\end{array}$ & Prob>Qui-Quadrado \\
\hline $\begin{array}{l}\text { Preço do boi magro } \\
\text { não causa preço do } \\
\text { boi gordo }\end{array}$ & 0,45336 & 1 & 0,501 \\
$\begin{array}{l}\text { Preço do boi gordo } \\
\text { não causa preço do } \\
\text { boi magro }\end{array}$ & 5,5516 & 1 & 0,018 \\
\hline
\end{tabular}

Fonte: Dados baseados na Seab e IEA (2012)

Como pode ser visto na Tabela 3, a hipótese nula de que o preço do boi magro não causa o preço do boi gordo não pode ser rejeitada a um nível de significância de 5\%. Porém, a a hipótese nula de que o preço do boi gordo não causa o preço do boi magro pode ser rejeitada, indicando que o preço do boi magro é influenciado pelo comportamento do preço do boi gordo, o que comprova a hipótese esperada.

Após o teste de causalidade de Granger mostrar que as duas variáveis, preço do boi gordo e preço do boi magro, são I(1), foi feito o teste de 
cointegração para verificar se as variáveis do modelo tendem a uma situação de equilíbrio de longo prazo. Para tal, foi escolhido o teste de cointegração de Johansen com a hipótese nula de que não há nenhum vetor de cointegração, ou seja, rank é igual a zero (Tabela 4).

Tabela 4 - Resultado do teste de Johansen para cointegração

\begin{tabular}{|c|c|c|c|c|}
\hline Hipótese Nula & $\begin{array}{l}\text { Hipótese } \\
\text { Alternativa }\end{array}$ & Eigenvalue & Traco & Valor crítico \\
\hline Rank=r & Rank $>\mathbf{r}$ & & & \\
\hline 0 & 0 & 0.04705 & 7.4252 & 15.41 \\
\hline 1 & 1 & 0.00373 & 0.5340 & 3.76 \\
\hline
\end{tabular}

Fonte: Dados baseados na Seab e IEA (2012)

Pelo teste de cointegração de Johansen, constatou-se que não há vetor de cointegração, pois a hipótese nula não foi rejeitada, já que o valor calculado da estatística traço é menor que o valor tabelado $(7,4252$ $<15,41)$. Sendo assim, as variáveis endógenas são perfeitamente correlacionadas, não sendo necessária a correção.

Como o número de vetores é igual a zero, o modelo a ser ajustado é um modelo autor- regressivo vetorial (VAR), nas diferenças. A Figura 1 apresenta os resultados da decomposição da variância.

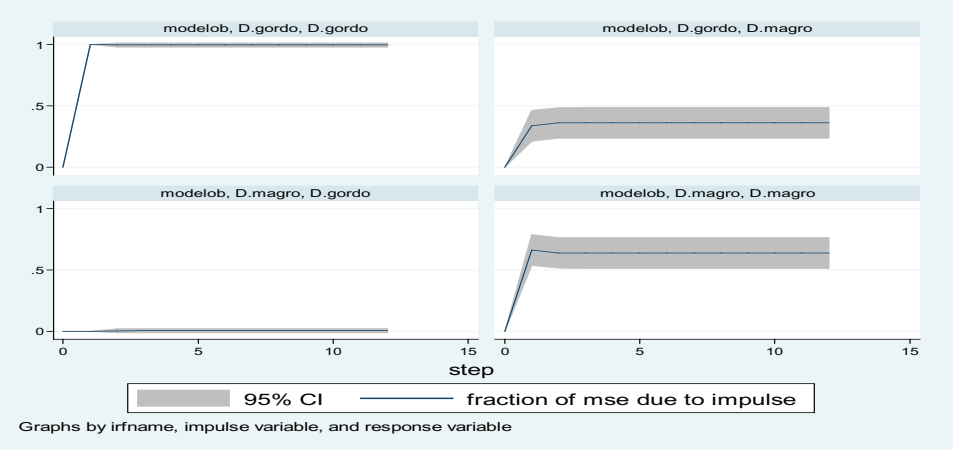

Figura 1 - Decomposição da variância

FONTE: Dados baseados na Seab e IEA (2012) 
Já que as séries temporais estudadas são de frequência mensal, foi utilizada a análise da função impulso-resposta para o período de 12 meses, depois de um choque (Figura 2).

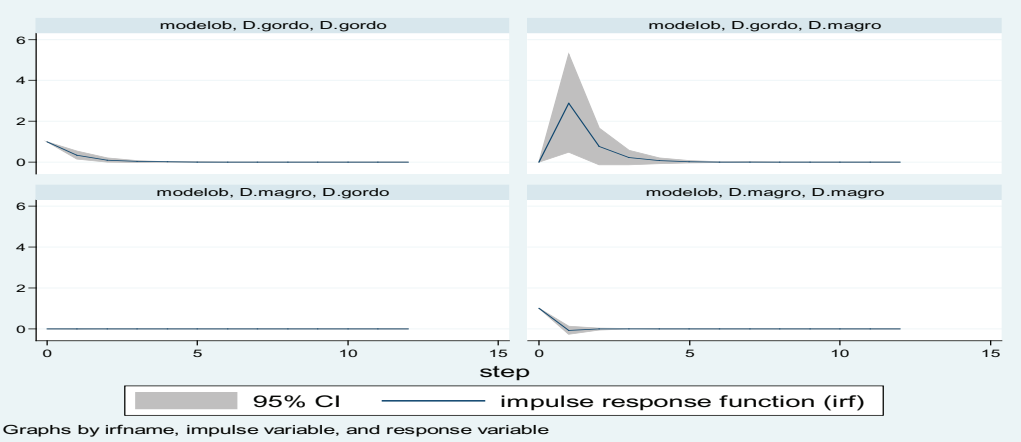

Figura 2 - Função impulso resposta das séries temporais analisadas FONTE: Dados baseados na Seab e IEA (2012)

A Figura 2 mostra que um choque não antecipado nos preços do boi gordo causa um alto impacto no mercado de boi magro no primeiro mês, reduzindo-se nos meses subsequentes e se estabilizando a partir do quarto mês, o que mostra que existe um forte relacionamento entre as variáveis estudadas. Por outro lado, choques não antecipados no preço do boi magro não geram impactos no preço do boi gordo. Então, os efeitos dos choques nas duas variáveis são de curta duração, já que após o quarto mês pós-choque há uma estabilização.

Para confirmar os resultados do modelo, a série foi seccionada em dois períodos, o primeiro de outubro de 2000 a outubro de 2006, e o segundo de outubro de 2006 a outubro de 2012, sendo utilizada a mesma metodologia da análise com toda a amostra. O resultado foi idêntico: o preço do boi gordo causa, no sentido de Granger, o preço do boi magro, sem relação de equilíbrio de longo prazo. 


\section{Conclusão}

O presente trabalho teve como objetivo examinar o comportamento dos preços do boi gordo e do boi magro na pecuária de corte brasileira entre outubro de 2000 e outubro de 2012. Para atingir o objetivo, foram utilizados os seguintes mecanismos: testes de Raiz Unitária de DickeyFuller Aumentado (ADF), de Causalidade de Granger, Cointegração de Johansen, o Método Autorregressivo (VAR), decomposição dos erros da variância e estimação da função impulso-resposta.

A análise leva a concluir que existe relação entre os preços do boi gordo e do boi magro, já que os resultados mostram que o preço do boi gordo causa, no sentido de Granger, o preço do boi magro, o que significa que preços passados do boi gordo ajudam a prever o comportamento do boi magro. Já o teste de cointegração mostrou que as variáveis analisadas não são cointegradas, ou seja, não têm relação de equilíbrio de longo prazo. Porém, no curto prazo, o preço do boi magro é influenciado pelo preço do boi gordo. Isto pode ser visto também nos resultados da decomposição da variância.

A explicação principal para os resultados encontrados é o ciclo da pecuária, ou seja, o preço pago pelo boi depende da disponibilidade do boi gordo e este das pastagens ao longo do ano. Assim, a cotação do boi acarreta redução das cotações das fases intermediárias até que as matrizes sejam descartadas, amenizando o excesso de oferta da carne bovina e, consequentemente, a queda nos preços.

O maior impacto nos preços do boi magro é causado por choques não antecipados no preço do boi gordo e acontece, fortemente, no primeiro mês e vai se reduzindo até o quarto mês, quando o mercado volta ao equilíbrio. No período analisado, alguns fatos externos à cadeia ocorreram e a influenciaram, tais como mudanças no cenário cambial (desvalorização cambial), redução da taxa de juros e aumento do salário mínimo, o que fez aumentar a demanda por carne bovina. 


\section{Referências}

ASSOCIAÇÃO BRASILEIRA DAS INDÚSTRIAS EXPORTADORAS DE CARNE. Exportações brasileiras de carne bovina crescem $6 \%$ em receita em julho. Disponível em: $<$ http://www.abiec.com.br/>. Acesso em: 28 novembro de 2012.

BATALHA, M. Estudo sobre a eficiência econômica e competitividade da cadeia agroindustrial da pecuária de corte no Brasil. Brasília, DF: Instituto Evaldo Lodi, 2000.

BATALHA, M. O. Análise da competitividade da cadeia agroindustrial de carne bovina no Estado do Paraná. Curitiba: IPARDES, 2002.

BRASIL. Ministério da Agricultura, Pecuária e Abastecimento. Secretaria de Relações Internacionais do Agronegócio. Balança Comercial do Agronegócio. Brasília, DF, 2007.

BUAINAIN, A. M.; BATALHA, M. O. (Coord.). Cadeia produtiva da carne bovina. Brasília, DF: IICA: MAPA/SPA, 2007. 86 p. (Agronegócios, v. 8).

EMBRAPA. Estudo sobre a eficiência econômica e competitividade da cadeia agroindustrial da pecuária de corte no Brasil. Brasília, DF: IEL: CNA: SEBRAE, 2000.

ESTADOS UNIDOS. Department of Agriculture (USDA). Disponível em: < http://www.usda.gov/wps/portal/usda/usdahome> Acesso em: 25 novembro de 2012

ESTATÍSTICA Brazilian Beef: exportação Disponível em: < http://www. brazilianbeef.org.br>. Acesso em: 29 novembro de 2012.

ESTATÍSTICA Brazilian Beef: Mercado Mundial Disponível em: < http://www.brazilianbeef.org.br>. Acesso em: 29 novembro de 2012. 
ESTATÍSTICA Brazilian Beef: séries históricas Disponível em: $<$ http:// www.brazilianbeef.org.br>. Acesso em: 20 novembro de 2012.

FAVERET FILHO, P.; PAULA, S. R. L. de. Exportações de carne bovina: desempenho e perspectivas. BNDES Setorial, Rio de Janeiro, n. 14, p. 27-46, set. 2001.

FOOD AND AGRICULTURE ORGANIZATION OF THE UNITED NATIONS. cattle meat production Disponível em: $<$ http://faostat.fao. org/default.aspx>. Acesso em: 25 novembro 2012.

FOOD AND AGRICULTURE ORGANIZATION OF THE UNITED NATIONS. Food Supply Quantity (Kg/Capita/Yr) Disponível em: $<$ http:// faostat.fao.org/default.aspx>. Acesso em: 28 novembro 2012.

FOOD AND AGRICULTURE ORGANIZATION OF THE UNITED NATIONS. Food Supply Quantity (tones) Disponível em: $<$ http://faostat. fao.org/default.aspx>. Acesso em: 30 novembro 2012.

GRANGER, C.W.J. Investigating causal relationships by econometric models and cross spectral methods. Econometrica, v 37, p.424-438, 1969.

GREENE, W.H. Econometric Analysis. 5º ed. Prentice Hall, 2003

GUJARATI, D. Econometria Básica. Tradução de Maria José Cyhlar Monteiro. 5 ed. Rio de Janeiro: Elsevier, 2010. 812 p.

IBGE. Sistema IBGE de recuperação automática: SIDRA. Disponível em: $<$ http://www.sidra.ibge.gov.br/bda/pecua $>$. Acesso em: 20 novembro 2012.

JOHANSEN, S. Statistical analysis of cointegration vectors, Journal of Economic Dynamics and Control, Vol.12, p. 231-254, 1988

MACEDO, L. O. B. Perfil de governança e a coordenação de alianças estratégicas do sistema agroindustrial da carne bovina brasileira. 
2009. Tese (Doutorado em Economia)-Escola Superior de Agronomia Luiz de Queiroz, Piracicaba, 2009.

MARTINS, S.S.; PINATTI, E.; IGREJA, A. C.M. Cadeia produtiva da pecuária de Corte: Ciclos pecuários e indicadores de lucro bruto. IN: CONGRESSO DA SOCIEDADE BRASILEIRA DE ECONOMIA, ADMINISTRAÇÃO E SOCIOLOGIA RURAL, 47, 2009, Porto Alegre. Anais... Porto Alegre, 2009. Comunicação - CD ROOM.

MEDEIROS, S. A. F. de. Agropecuária brasileira: balanço 2006 e perspectivas 2007. Brasília, DF: CONFEDERAÇÃO DA AGRICULTURA E PECUÁRIA DO BRASIL, 2007.

NEHMI FILHO, V. A. Novo ciclo de alta da pecuária começa em 2007. Anuário da Pecuária Brasileira 2007. São Paulo: Instituto FNP, 2007. p. 16- 17.

PECUÁRIA Brazilian Beef: Halal e Kosher Disponível em: < http:// www.brazilianbeef.org.br>. Acesso em: 19 abr. 2010.

PEREZ, R. Uma análise explanatória da competitividade e agregação de valor da cadeia produtiva de carne bovina no Brasil, com ênfase no segmento de abate e processamento. 2003. 336p. Tese (Doutorado)Unicamp, Campinas, SP, 2003.

PIGATTO, G. Determinantes da competitividade da indústria frigorífica de carne bovina do estado de São Paulo. 2001. Dissertação (mestrado) - UFSCAR, São Carlos, SP, 2001.

PITELLI, M. M. Testes de preço para a determinação do mercado relevante geográfico e de produtos: uma aplicação empírica ao mercado brasileiro de compra de bovinos. 2008. Tese (doutorado) ESALQ, Piracicaba, SP, 2008.

PRADO, I. N. do; SOUZA, J. P. de. Cadeias produtivas: estudos sobre competitividade e coordenação. 2. ed. Maringá: Eduem, 2009. 
SACHS, R.C.C ; PINATTI, E. Análise do comportamento dos preços dos preços do boi gordo e do boi magro na pecuária de corte paulista, no período de 1995 a 2006. Revista de Economia e Agronegócio, V.5, n. 3, 2008 .

SIFFERT FILHO, N.; FAVERET FILHO, P. O sistema agroindustrial de carnes: competitividade e estrutura de governança. BNDES: O Banco Nacional de Desenvolvimento, Rio de Janeiro, v. 5, n. 10, p. 265-297, 1998. Disponível em: <http://www.bndes.gov.br/SiteBNDES/ bndes/bndes_pt/Institucional/Publicacoes/Consulta_Expressa/Setor/ Agroindustria/199812_18.html >. Acesso em: 12 jun. 2010.

VINHOLIS, M. M. B. Uma análise da aliança mercadológica da carne bovina baseada nos conceitos da economia dos custos de transação. In: WORKSHOP DE GESTÃO DE SISTEMASAGROALIMENTARES, 1999. Ribeirão Preto. Anais... Ribeirão Preto: USP, 1999. 
REVISTA DE ECONOMIA E AGRONEGÓCIO, VOL.11, $N^{\circ} 3$ 